\title{
Special features of corporate budget planning: contemporary approach
}

\author{
Tatiana Bondarenko, ${ }^{1, *}$, Galina Panaedova ${ }^{2}$, Lira Gurieva ${ }^{3}$, Tatiana Belyanchikova $^{4}$, Irina \\ Mityushina $^{5}$ \\ ${ }^{1}$ Plekhanov Russian University of Economics, 36, Stremyanny lane, Moscow, Russian Federation, \\ ${ }^{2}$ Federal University, Pushkin str. 1, Stavropol, Russian Federation, \\ ${ }^{3}$ North Ossetian State University named after K.L. Khetagurov, , Vatutina str.44-46, Vladikavkaz, \\ 362025, Russian Federation \\ ${ }^{4}$ Financial University under the Government of Russian Federation, , Leningradskij pr. 49, Moscow, \\ Russian Federation \\ ${ }^{5}$ Belgorod National Research University, Pobedy Street 85, Belgorod, 308015, Russian Federation
}

\begin{abstract}
The purpose of this article was to study budgeting process from the point of its structure, analyze the Russian and European models of budget planning. Russian experts seem to favor a combination of rolling budgeting and top-down approach. Zero based method is preferred for larger projects with strict budgeting culture. For smaller and medium business, there remains lack of attention to budgeting. It is caused by lack of finance, experience and prioritization of other financial management tools. The classical approach used in the beginning stage would definitely be the topdown approach, which despite some its flaws can work well in the beginning stage of business development, when the strategy is rather aggressive and growth-oriented. Larger better-established organizations tend to realize importance of budgeting process and devote greater attention to developing its structure. The combination of methods is rather appropriate and additional investment should be made specifically into the Information System used in the budgeting process, as it is associated with reducing labor costs and accelerating processes. Unfortunately, Russian companies still find it difficult to keep up with development of new techniques on budgeting process overseas. This was shown in detailed comparison of Russian budgeting model with the European one.
\end{abstract}

\section{Introduction}

Budgeting takes a crucial part in corporate management, as it can be a form of financial reflection of strategic goals of a company, as well as logical base for analysis of performance results and even a management motivation element.

The budgeting process can be understood as a procedure for analysing management

\footnotetext{
*Corresponding author: aib-2004@yandex.ru
} 
decisions made in the past, through which the rationality of using all currently available assets, as well as the sources involved, is assessed. Budgeting is a kind of a guide for a company, a base of initial information for analysing activities and evaluating work efficiency [1]. Thanks to the budget, it is possible to translate the planning system, presented in natural and physical units, into a system of financial indicators $[2,3,4]$.

Budgeting allows you to significantly increase the efficiency and rationality of the use of resources available to the company, as well as draw up the boundaries of responsibility among managers at various levels of the organizational structure of the enterprise. Budget planning provides management with the means to investment opportunities of the company in terms of assets, that are can attract the most income into the company. It is important, that presence of a well-built and implemented budgeting system make the company "financially transparent" for both investors, managers, and external users of information [5]. Budgeting helps to strengthen financial discipline within the organization, to motivate all structural units of the enterprise in the interests of the company work more efficiently as a whole $[6,7]$. The most important benefit of budgeting, however, is that it allows you to constantly monitor the financial situation in the organization, which consequently leads to increased financial stability of a company.

In accordance to the defining principles of budgeting, this process is required to be:

- complete as it should cover all types of activities and all departments of the organization;

- focused on the needs of the market with priority in selling products from production, taking into account the limits of resources that are available to the organization;

- based on rational norms and standards, using progressive methods for their development;

- integrated so that the execution of budgets of the lowest level affects the execution of budgets of the highest level as the greatest measure;

- flexible as it should allow for the possibility of adjustment to changing external factors as well as strategic position of the organization;

- allow for costs to be rationally correlated with the results.

The most used approaches today go as follows:

- top-down;

- bottom-up;

- flexible;

- rolling;

- zero-based budgeting;

- beyond budgeting [7].

Unfortunately, today corporate budgeting is still in the beginning stage of its development and lacks a clearly defined structure, that could be implemented in companies' corporate planning process, which means that only bigger more established firms chose to devote time and finance for development of a thought trough well-structured budgeting process. For this reason, smaller businesses have hard time making use of their budgets and getting the most information out of them, which could be used for strategy revision and further development and growth of a company. That is why the topic of budgeting structure and implementation control stays relevant today. Financial results of a company have a direct connection to its budgeting process from the financial planning standpoint as of the main elements of corporate financial management.

\section{Literature review}

New features of corporate budget planning is an active link in all spheres of society. It is impossible to imagine the modern world without innovations that have already taken place 
and which have become habitual, and without future ones that contribute to further evolution.

Kazakhstan researchers as Sayabek Ziyadin, Aizhan Omarova, Raigul Doszhan, Gulnara Saparova, Gulim Zharaskyzy wrote about the rapid growth of the market of scientific and technical products and the high level of competition, market appropriate solution becomes finding ways to commercialization of research products $[8,9]$.

Another one meaning of Ziyadin S., Suieubayeva, S., Utegenova, A. is that the research contains a literature review which is giving insight into the fundamental comprehension of digital transformation. Findings indicate that even though digital transformation is a wellknown idea a method for the organized digital transformation of business models is missing [10].

Ziyadin S., Streltsova, E., Borodin, A., et al. researched the creation of intelligent modelling tools for decision support in the evaluation of intellectual projects submitted for financing, as based on qualitatively defined characteristics. The economic and mathematical models that form the basis of the toolkit are constructed using the mathematical apparatus of fuzzy logic, which allows for the description of poorly structured knowledge of specialists, as well as their application in solving questions about the extent of the impact of the proposed projects on the environment [11].

Joshi, P. L., Al-Mudhaki, J., \& Bremser, W. G. wrote in their research about the the study findings suggest the need for research on attitudes held by the budgetees towards the use of budget variances in the context of advanced management accounting techniques [12].

Merchant, K. A. researched about the differences in corporate level budgeting systems are related to corporate size, diversity, and degree of decentralization and how different choices in system design and use are related to ofganizational performance and manager motivation and attitudes [13].

Jensen, M. in his research work described the counterproductive effects associated with using budgets or targets in an organization's performance measurement and compensation systems [14].

Concidine, M. in his work determined the program budgeting, corporate planning, performance contracts, program evaluation and new forms of efficiency scrutiny are among the techniques introduced [15].

According to Mutanov, G., Ziyadin, S., Shaikh, A., recently, the intensity of digital technology and innovation has been largely reflected in the level of sustainable economic development. In the context of global competition, this can be seen in those countries that provide favorable economic conditions and the benefits associated with innovation. The development of an innovative economy is an important prerequisite for increasing the country's competitiveness $[16,17]$.

Ideally, to maintain competitiveness, budgeting aimed at long-term existence should be accompanied by a continuous search and implementation of innovative solutions. Although, often, innovations encounter certain difficulties of implementation, they are a source / reserve for a significant increase in the efficiency of individual processes. This is especially necessary during periods of industrial crisis, when the optimization of production processes, cost reduction, increased sales efficiency due to the creation of new products, etc. take an important direction of development.

\section{Methods}

A range of methods of enquiry was engaged in this work, including the dialecticmethod, general scientific methods and special methods of research, such as analysis, synthesis, analogy and classification, as well as the historical and logical methods, which suit the textual material naturally and make it wholly comprehensive. The application of the systematic 
approach in studying the Russian budgeting model with the European one has helped to produce a comprehensive study.

The paper's information base includes official Russian and international statistical information resources, data from official websites of research agencies and institutions covering the tools of process of budgeting model's formation.

\section{Results and Discussion}

\subsection{Setting up the corporate budgeting process by the classic Russian model}

The budget process is not limited only to the stage of drawing up the consolidated budget.

In general, the process is a cycle of financial management, which includes three consecutive stages (Fig. 1):

- the stage budget draft development;

- approval of the draft budget and its inclusion in the structure of a scientifically based business plan for the next year;

- monitoring and control of current budget implementation, as well as analysis of its efficiency.

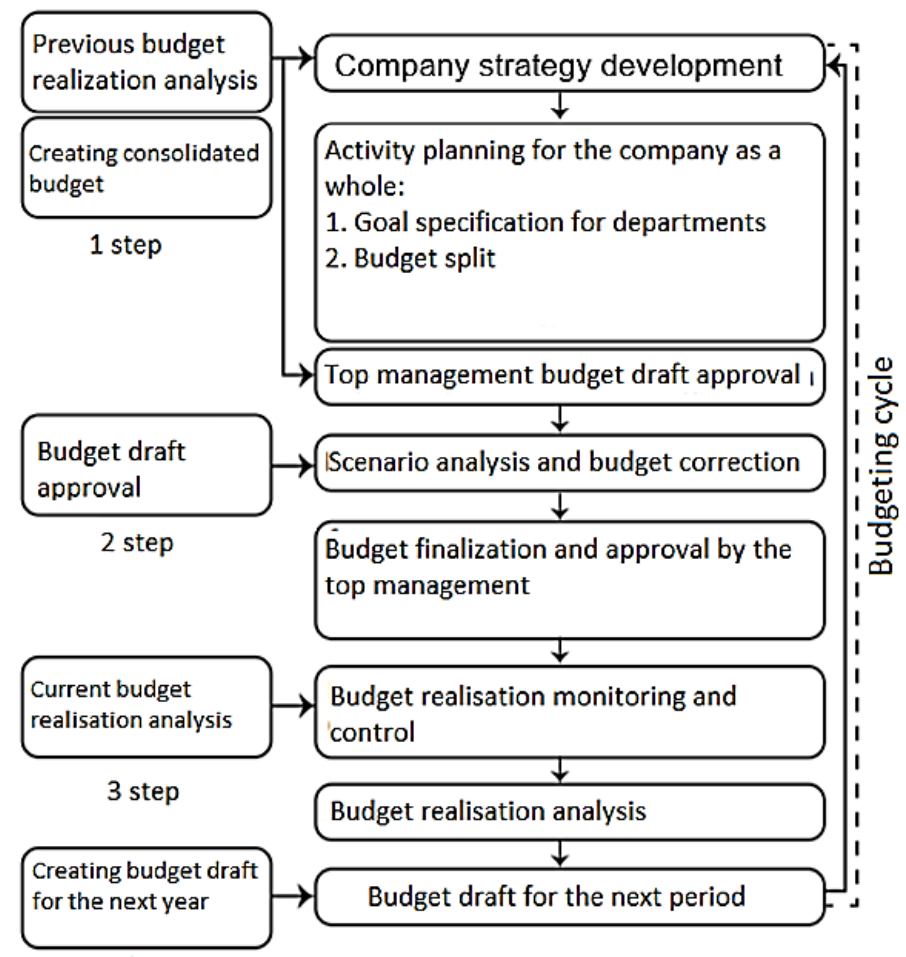

Fig. 1. Basis structure of budgeting system in a small Russian company.

The budget cycle is a period from the very beginning of the first stage to the completion of the third. The budget process should be continuous, which means that the completion of the analysis of budget execution for the current year should be followed by the development of the budget for next year. Thus, it can be said that the analysis of budget execution is simultaneously the starting and the final stage of the budget cycle. 
The first stage (the stage of the draft development and budget consolidation) consists of a preliminary draft budget for the next planning year. Particular attention has to be paid to assessing the implementation of profit and profitability plans. Such an assessment should be based on careful and thorough development of the composition of costs included in the production cost. At this stage, the production program is evaluated (its qualitative and quantitative parameters, changes in price and credit policies) and the new production potential of the organization is defined by the analysis of the rational use of available assets, development of new technologies and product types.

The prepared budget draft is adjusted in accordance with changes in external and internal conditions.

The first stage requires involvement of a large number of ordinary personnel of planning and economic services and structural divisions, which approve budget tasks: workshops of the main production, commercial directorate (sales department), logistics department, etc.

The second stage (approval stage) is the preparation of the final draft budget and its inclusion in the structure of a business plan of the enterprise. In small companies, the consolidated budget is usually developed by the accounting department with the use of excel as sophisticated information systems are not implemented yet. The budget is later approved by the president of the organization.

An approved budget is considered a guide to future activity.

At the third stage, an analysis of budget execution is carried out based on the results of the past year, as well as an analysis of the financial condition of the enterprise, following which the necessary adjustments are made to the strategy direction and goals of the economic development of the organization.

To summarize, it is worth noting the following points.

Firstly, at the initial stages of introducing a budgeting system, the company will most likely use the top-down method in its pure form, as seen in the prior example. This method is not considered optimal, but it is with the help of it that management will be able to consolidate their strategic goals for the future development of the company as part of budgeting. Despite the shortcomings of the top-down method, it can become a really useful starting point for the subsequent development of the company, whether it be product development and growth of the market share of the business or maintaining a stable balanced flow.

It is assumed that the legal status of most young company does not oblige them to publish their financial results. In this case, the budgeting cycle is not limited to the global calendar, and can be started at any time. Nevertheless, it is important to remember that with further development the company may transfer to a joint-stock company, for example, which will result in the obligation to publish financial statements at least once a year at the end of December depending of the type of the market sector.

It is recommended though that the company begins the budget cycle in January as a the common market practice goes to avoid any difficulties of future transition.

\subsection{Setting up the modernized corporate budgeting process in Russia}

Let us assume that our company has foregone multiple stages of development and growth and transformed into a well-established organization, the basic budgeting system used prior becomes insufficient in new business situation. If the company is aimed at growth and competitiveness, top management should be aware of the need for additional investment to improve the budgeting system.

As noted earlier, Russian companies submit their financial statements at the end of December, which automatically shifts the start of the budget process to January that is the beginning of a fiscal year (Fig. 2). 


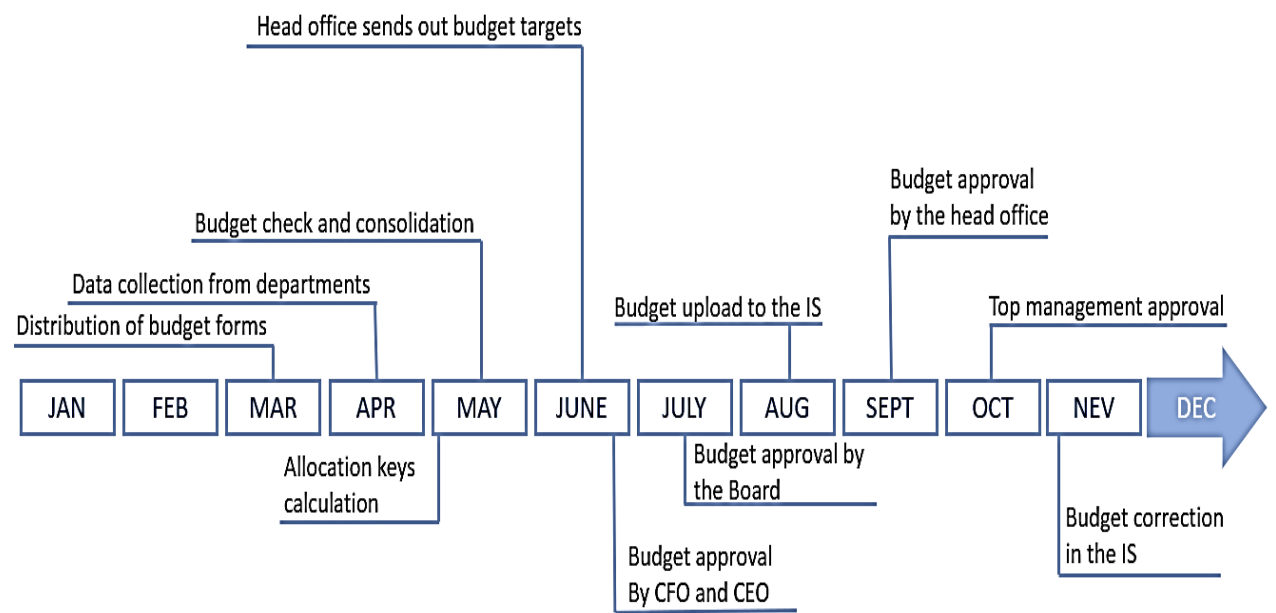

Fig. 2. Modernized budgeting structure for a well-established company in Russia.

It is important to note that in this budgeting structure, the already mixed top-down bottomup approach is used. As was assessed in the first chapter, combining various budgeting approaches is a rather smart idea as it helps to avoid some shortcomings and potential unpleasant consequences of implementation of both methods separately and to achieve the most efficient budget process tailored for a particular company.

In this case, the budgeting process is stated with budget forms being sent out to organization units that should can design their part of the budget based on their needs and indicators of past performance experience within a month.

Next, the allocation keys are calculated, which will be included in the budget as requirements and thresholds, restrictions and even additional items of income and expenses of the enterprise. Allocation keys should be understood as external and internal factors that can have an effect on the implementation of the budget and financial results of the company. Internal factors, for example, will include a planned investment project costs, which must be taken into account in the company's expenses budget.

It is also necessary to pay great attention to external factors. Those must be laid down in the budget plan as well. Let's consider a few forecasted key parameters of the Central Bank of Russia for 3 scenarios for the year 2020. They should not be ignored by companies, as they attempt to illustrate future economic state of the country, which reduces unpredictability of the market in a significant way. The indicators, reflected in Monetary Policy Guidelines for 2020-2022 are listed in the table 1. Let us consider every single one of them individually.

Table 1. Forecast of key parameters for 2020 by the Central Bank of Russia.

\begin{tabular}{|l|c|c|c|}
\hline $\begin{array}{c}\text { Parameters (growth as \% of previous } \\
\text { year, unless indicated otherwise) }\end{array}$ & Risk scnenario & Baseline & $\begin{array}{c}\text { High oil } \\
\text { price }\end{array}$ \\
\hline Inflation as an average \% for the year & $6,0-7,5$ & $3,5-4,0$ & $3,1-3,5$ \\
\hline GDP & $-(1,5-2,0)$ & $1,5-2,0$ & $2,0-2,5$ \\
\hline Exports & $00-0,5$ & $2,0-2,5$ & $2,7-3,2$ \\
\hline Imports & $-(12,5-13,0)$ & $3,0-3,5$ & $3,3-3,8$ \\
\hline Source: created by author based on Monetary Policy Guidelines for 2020-2022 \\
\hline
\end{tabular}


All budgeted indicators have to be adjusted for expected growth of inflation it has effect on all financial aspects of the company, so in has to be accounted for in all forecasts and budgets.

When the company management sees that GDP is forecasted to grow by 2 percent next year, they can assume that consumption rate is going to grow with it, so the cause y can adjust production plans by $2 \%$, which will entail revenue growth as well as the production cost growth by $2 \%$ accordingly.

Export growth by 2.5 percent will entail revenue similar revenue and production cost rise. However, import growth by $3 \%$ will not only increase revenue and production cost accordingly, it will actually reduce some of the cost allocated for material purchase (if it is raw materials that are imported) connected with the cheaper selling price of imported goods rather than local, which will have a direct impact of profit increase.

In addition, such indicators as the Central Bank key rate and the national currency rate should be included in the budget.

The problem is the difficulty in predicting the values of these indicators. For any kind of forecasts, it is again recommended to consider several scenarios. In any case, specialists in financial and economic services should rely on their experience and analysis of external experts and use their professional vision and experience to consider these factors in the preparation of budgets.

This issue was discussed at the annual CFO Russia 2018 conference. As the discussion showed, there is a great scatter of opinions of specialists regarding the ruble exchange rate and inflation rate. In general, however, all predictions fit in between the forecasts of the most pessimistic and optimistic scenarios. Since errors in forecasting will affect the results of operations, their assessment falls under the responsibility of specialists in the field of planning and budgeting, therefore, at least two budget scenarios are drawn up at most enterprises - real (basic) and pessimistic, similarly to the way Central Bank approaches forecast of its indicators. Only after all of the allocation keys have been identified and taken into account, the budget drafts of the organization units go through internal audit. After everything is checked and validated, the master budget is consolidated and is sent to the head office, where it has to be compared with the strategic and budget goals and targets set by the top management of the company. Corrections are made in accordance with the overall established goals and then the budget goes through all the necessary stages of final approval.

It is also important to pay attention to the next step in the budgeting process downloading budget targets into the information system (IS). In the process of developing a budgeting system, one of the most significant stages is the transition to specialized software and automation of routine processes. This investment is justified by minimizing errors related to the human factor along with reducing labor costs and accelerating processes. Often, the proposed information systems carry a variety of functions that make it possible to simplify the budgeting process at many stages, from developing budgets to departments and ending with the possibility of certified approval by each authorized stakeholder on time.

Of course, the whole process from beginning to end is accompanied by continuous monitoring of the implementation of the current budget. The period from January to February is allocated for a detailed analysis of the implementation of last year's budget, identification of unfulfilled goals and allocation of the problems that could have caused them. The results of this analysis should primarily be taken into account when forming the draft budget for the next year

\subsection{Special features of corporate budget planning be the European model}

Now we will consider the next development stage of our company and how the budgeting process can be adapted if it enters the global group of companies with headquarters in Europe. 


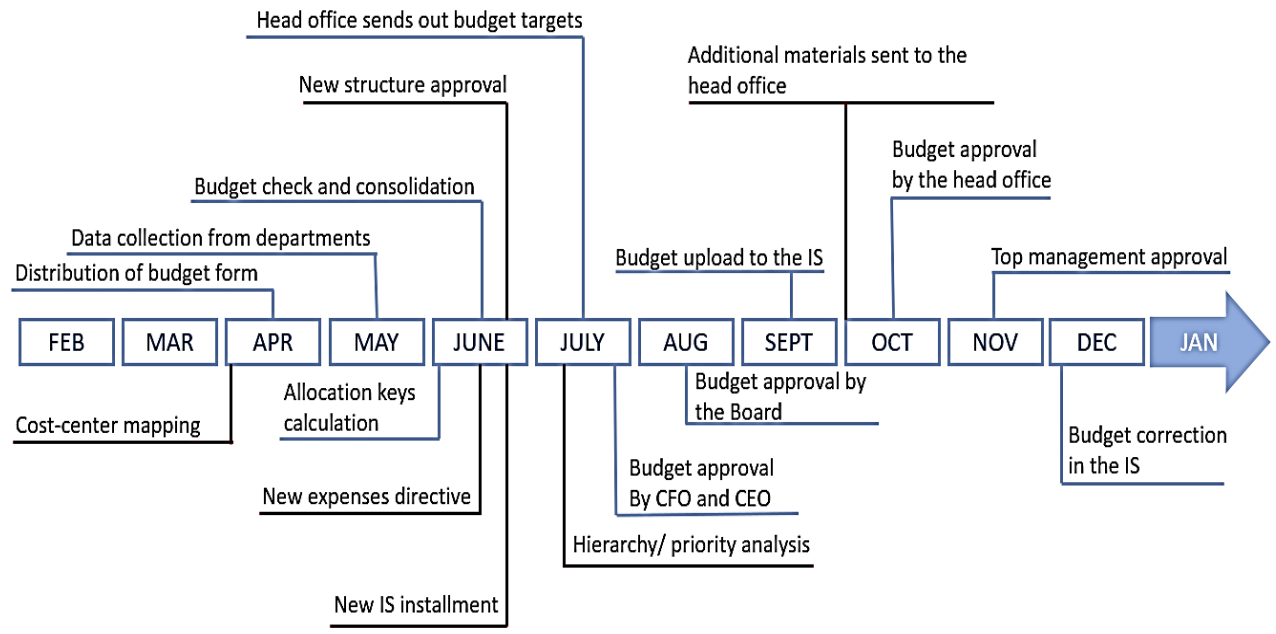

Fig. 3. European model of budgeting structure.

It is noteworthy that due to the fact, that the company was acquired by the European Group, it also incurs the obligation to follow the rules of European financial reporting, and therefore the beginning of the budget process moves to February, since by European standards the reporting month is January and the fiscal year begins in February. One of the most effective and widely used modern financial planning tools is mapping, it is implemented as part of best practices worldwide, but is not yet that established in Russia. This method is quite intuitive as it consists of drawing up a mental map that allows you to visualize various aspects of the business.

In constructing a "mental map" for planning and expanding a business, three main aspects are usually considered:

Assessment of risks associated with the activities of the company. As the main risk, many experts call an overrun of the budget allocated for the project. There can be many reasons for this - non-optimal allocation of resources, shortcomings in the planning of time, incorrect definition of the project framework, illiterate personnel policy, difficulties associated with achieving planned targets, errors during the marketing company, changing market conditions, and the global financial crisis, and data loss, and natural disasters, and etc. The question of how safe the campaign is (in terms of return on investment, or ROI) and whether any profit is guaranteed is of a great importance. Development planning. A successful company must grow, expand its presence in the market, absorb other companies and open branches, fighting for new customers. When planning business development, mapping helps to keep in mind existing customers, create strategy and budget concerning additional products and services for them, provide advice, conduct seminars and events [18]. Study of the details of the upcoming expansion. It is necessary to clearly define the nature of the activity, as well as its goals and objectives. It is necessary to take into account all the nuances associated with partners, customers, and staff. You need to plan the time and place of the campaign and assign tasks to time. All the aspects listed above can and should be displayed on the "mental map". Thus, the management will receive not just a financial plan for a certain period, but an integral picture of the current and future financial situation in the company. By creating such a map, you are able to go beyond the usual accounting documents, each of which covers only one 
specific aspect of the situation. Mapping broadens the horizons of the financier, allowing him to clearly see the effect of combinations of the factors considered on the situation as a whole.

When acquiring a company with a developed and extensive hub structure throughout the country, mapping will allow the head office to analyze the cost centers of the newly acquired company and decide on the need to merge them in order to minimize costs or open additional offices to increase the efficiency of the enterprise with a subsequent positive effect in the form of an increased revenue. It is at this point that some hidden structure flaws can be preliminary uncovered and eliminated. It is natural that the parent company will have to review a lot of the foundational features of the company to evaluate the efficiency of its operation overall and those processes will need to be included into the expanded budgeting process. As the new owners establishe his control over the final decision making, it is necessary to work out and approve the new structure of the company, which will be a direct result of the mapping mentioned earlier. Restructurization might lead to the closing of some of the brunches of the company or general staff reduction in order to cut costs, if the operation was deemed to be neither cost-efficient, nor profitable, and the new head office was not able to see any potential in it. Hierarchy analysis allows the management to establish priority budget zones. The research conducted by the author concerning budgeting approaches and methods showed the existence of such potential risk as "budget wars" in between different departments, as each one will strive to rise the expenses plan in order to make the planned indicator easier to be achieved. For this reason its is crucial for management to create a hierarchy of budget expenses to have a clear idea of what to do in case of lack of funds, and which budget goals are of the highest priority.

\section{Conclusion}

Budgeting is a complex process of formation, coordination, approval of budgets and control over their actual implementation, including constant analysis and monitoring as well as regular reviews and corrections of it.

Russian experts seem to favour a combination of rolling budgeting and top-down approach. Zero based method is preferred for larger projects with strict budgeting culture. However, for smaller projects beyond budgeting seems to be the most appropriate. No approach should be used in its pure form, it is considered to be the most rational to combine approaches in order to tailor the budgeting process specifically for the company's needs.

For smaller and medium business, there remains lack of attention to budgeting. It is caused by lack of finance, experience and prioritization of other financial management tools. The classical approach used in the beginning stage would definitely be the top-down approach, which despite some firsts flaws can work well in the beginning stage of business development, when the strategy is rather aggressive and growth-oriented. Larger betterestablished organizations tend to realize importance of budgeting process and devote greater attention to developing its structure. The combination of methods is rather appropriate and additional investment should be made specifically into the Informational system used in the budgeting process, as it is associated with reducing labor costs and accelerating processes. Unfortunately, Russian companies still find it difficult to keep up with development of new techniques on budgeting process overseas. This was shown in detailed comparison of Russian budgeting model with the European one.

\section{References}


1. K. Aljifri, M. Moustafa, The Impact of Corporate Governance Mechanisms on the Performance of UAE Firms: An Empirical Analysis. Journal of Economic and Administrative Sciences, 23 , 71-93 (2007) https://doi.org/10.1108/10264116200700008

2. Borodin A., Shash N., Panaedova G. , Frumina S., Kairbekuly A., Mityushina I. Entrepreneurship and Sustainability Issues, 7, 1666-1685 (2019)http://doi.org/10.9770/jesi.2019

3. Gurieva L., Borodin A., Berkaeva A. 1st International Scientific Conference "Modern Management Trends and the Digital Economy, 81, 385-389 (2019) https://doi.org/10.2991/MTDE-19.2019.73

4. A.G. Kankia, Economics and Innovations Management, 3 (2013)

5. Natocheeva N., Borodin A., Rud N., Kutsuri G., Zholamanova M, Namitulina N. Entrepreneurship and Sustainability Issues,7,1654-1565 (2019) http://doi.org/10.9770/jesi.2019.

6. Hocheol Nam, Konari Uchida, Journal of Banking \& Finance, 102, 116-137(2019). https://doi.org/10.1016/j.jbankfin.2019.03.010

7. M. Skare, M. Porada-Rochoń, Journal of Economics and Economic Policy, 14, 7-29 (2019) https://doi.org/10.24136/eq.2019.001

8. Mukhtarova, K., Ziyadin, S., Kupeshova, S., \& Doszhan, R. Economic annals-XXI, (168), 38-43 (2017)

9. Sayabek Ziyadin, Aizhan Omarova, Raigul Doszhan, Gulnara Saparova and Gulim Zharaskyzy. Problems and Perspectives in Management, 16(4), 331-343. doi:10.21511/ppm.16(4).2018.27 (10) (2018).

10. Ziyadin, S., Suieubayeva, S., \& Utegenova, A. Digital Transformation in Business. (pp. 408-415) Springer, Cham (2019)

11. Ziyadin, S., Streltsova, E., Borodin, A., Kiseleva, N., Yakovenko, I., \& Baimukhanbetova, E. Sustainability, 11, (2019)

12. Joshi, P. L., Al- Mudhaki, J., \& Bremser, W. G. Corporate budget planning, control and performance evaluation in Bahrain. Managerial Auditing Journal (2003)

13. Merchant, K. A. The design of the corporate budgeting system: influences on managerial behavior and performance. Accounting Review, 813-829 (1981)

14. Jensen, M. C. Corporate budgeting is broken, let's fix it. Harvard business review, 94$101(2001)$

15. Considine, M. The corporate management framework as administrative science: A critique. Australian Journal of Public Administration, 47, (1988)

16. Mutanov, G., Ziyadin, S. /E3S Web of Conferences -2019-135, 04056 (2019) DOI: $10.1051 / \mathrm{e} 3$ sconf/201913504056 (2019)

17. Mutanov, G.; Ziyadin, S.; Shaikh, A. 2019. Entrepreneurship and Sustainability Issues 6(4): 2136-2158. http://doi.org/10.9770/jesi.2019.6.4(41)

18. Lebedeva, T. E., Akhmetshin, E. M., Dzagoyeva, M. R., Kobersy, I. S., \& Ikoev, S. K. International Journal of Economics and Financial Issues, 6(1S), 25-32. (2016). 